\title{
Naringin induces apoptosis of gastric carcinoma cells via blocking the PI3K/AKT pathway and activating pro-death autophagy
}

\author{
CUIXIANG XU ${ }^{1 *}$, XIAOYAN HUANG ${ }^{1 *}$, YUBIN HUANG ${ }^{2,3}$, XIAO LIU $^{2,3}$, \\ $\mathrm{MIN} \mathrm{WU}^{4}$, JIANHUA WANG ${ }^{3}$ and XIANGLONG DUAN ${ }^{3,5,6}$

\begin{abstract}
${ }^{1}$ Shaanxi Provincial Key Laboratory of Infection and Immune Diseases, Shaanxi Provincial People's Hospital, Xi'an, Shaanxi 710068; ${ }^{2}$ Clinical Department, Xi'an Medical University, Xi'an, Shaanxi 710021;

${ }^{3}$ Second Department of General Surgery; ${ }^{4}$ Department of Research, Shaanxi Provincial People's Hospital, Xi'an,
\end{abstract} \\ Shaanxi 710068; ${ }^{5}$ Department of General Surgery, Affiliated Hospital of Northwestern Polytechnical University, Xi'an, \\ Shaanxi 710072; ${ }^{6}$ Clinical Department, Tibet Nationalities University, Xianyang, Shaanxi 712082, P.R. China
}

Received December 7, 2020; Accepted April 19, 2021

DOI: $10.3892 / \mathrm{mmr} .2021 .12412$

\begin{abstract}
Naringin (Nar) is one of the natural glycosides extracted from pomelo and other citrus fruits. It has various pharmacological activities, including anti-inflammatory, antioxidant, anti-proliferative and anti-cancer. However, the underlying mechanisms by which Nar regulates apoptosis and autophagy in gastric cancer remain unclear. Thus, the present study aimed to assess the therapeutic effect of Nar and the underlying mechanisms. SNU-1 cell proliferation was determined using Cell Counting Kit- 8 assay. Cell morphological changes were observed under a phase-contrast microscope. The changes in the cell cycle were determined using flow cytometry analysis and the changes in cell apoptosis were determined using flow cytometry, Hoechst 33258 and TUNEL staining. The protein levels pertaining to the PI3K/AKT pathway and cell apoptosis and autophagy were monitored using western blot analysis. The results demonstrated that Nar significantly inhibited SNU-1 cell growth and induced cell cycle arrest in the $\mathrm{G}_{0} / \mathrm{G}_{1}$ phase and cell apoptosis. Further mechanistic studies demonstrated that Nar blocked the PI3K/AKT pathway, activated cell autophagy and stimulated the expression of apoptosis-associated protein cleaved caspase 3 and Bax, but decreased the expression of Bcl-2. Preincubating SNU-1 cells with 3-methyladenine, a cell-autophagy inhibitor, significantly alleviated the effects of Nar in promoting cell apoptosis and cleaved caspase 3 expression. It was concluded that Nar
\end{abstract}

Correspondence to: Dr Jianhua Wang or Dr Xianglong Duan, Second Department of General Surgery, Shaanxi Provincial People's Hospital, 256 Youyi West Road, Xi'an, Shaanxi 710068, P.R. China E-mail: wangjianhuaman@163.com

E-mail:65215657@qq.com

*Contributed equally

Key words: apoptosis, cell autophagy, gastric carcinoma SNU-1 cells, naringin, PI3K/AKT promoted SNU-1 cell apoptosis via blocking the PI3K/AKT signaling pathway and activating cell autophagy.

\section{Introduction}

Gastric cancer, one of the commonest malignancies, is the third leading cause of cancer-related deaths worldwide (1). The incidence and mortality rates of gastric cancer are declining every year due to the improved control of related risk factors and the development of screening techniques (2). However, the incidence rate of gastric cancer remains high due to the large population base of the world and the trend of population aging (3). The gastric cancer cases and deaths in China account for $50 \%$ of the total gastric cancer cases in the world. In China, the incidence rate of gastric cancer is higher in northwestern and eastern coastal areas than in southern regions $(4,5)$. Gastric cancer not only damages the digestive system but also affects the liver, kidney and respiratory functions once metastasis occurs. In severe cases, gastric cancer may lead to cachexia and ultimately become life-threatening (6). Surgery is the main treatment method for gastric cancer. Numerous patients with gastric cancer have witnessed an improvement in their conditions following surgery combined with chemo- or radiotherapies. However, a number of patients still suffer from recurrences and metastases after initial treatment. The effects of treatment and the 5-year survival rate are unsatisfactory (7). Therefore, new drugs and therapies for the clinical treatment of gastric cancer need to be urgently developed.

A number of studies have demonstrated that Chinese herbal medicines can effectively kill cancer cells and possess fewer problems in drug-resistance and toxic side effects (8). Naringin (4',5,7-trihydroxyflavanone-7-rhamnoside, Nar; Fig. 1A) is a natural glycoside, also called bioflavonoid, found in pomelo and other citrus fruits (9). Previous studies have shown that Nar has various pharmacological activities, including anti-inflammatory, antioxidant and cardioprotective effects and can regulate glucose and lipid metabolism $(10,11)$. Accumulating studies have also confirmed the anti-cancer activities of Nar through eliminating free radicals via its antioxidant effects and inhibiting oncogene expression and 
then inhibiting cancer cell proliferation and inducing cancer cell apoptosis (12-14). Nar can induce apoptosis and inhibit cancer cell growth in colorectal cancer, cervical cancer, ovarian cancer, liver cancer and other types of cancer (15-18). However, the effect of Nar on gastric cancer SNU-1 cells and its mechanism remain unclear.

The present study demonstrated the anti-cancer effect of Nar and its potential molecular mechanism through experimental research on gastric cancer cell line SNU-1, thus providing a new theoretical basis for further research on the anti-cancer effect of Nar and related molecular mechanisms.

\section{Materials and methods}

Experimental reagents. Gastric carcinoma cell lines (SNU-1; cat. no. CL-0474), normal human gastric epithelial cells (GES-1; cat. no. CL-0563) and fetal bovine serum (FBS) were purchased from Procell Life Science \& Technology Co., Ltd. RPMI-1640 medium was purchased from Gibco (Thermo Fisher Scientific, Inc.). The Hoechst 33258 staining solution (C1017), TUNEL Apoptosis Assay kit (C1088) and BCA Protein Assay Kit (P0012) were procured from Beyotime Institute of Biotechnology. The rabbit anti-human cysteinyl aspartate specific proteinase (caspase 3) antibody (1:1,000; cat. no. ab179517), rabbit anti-human $\operatorname{Bax}(1: 1,000$; cat. no. ab32503), rabbit anti-human Bcl-2 (1:2,000; cat. no. ab182858), rabbit anti-human microtubule-associated protein 1 light chain $3 \beta$ (LC3B; 1:3,000; cat. no. ab51520), rabbit anti-human Beclin (1:2,000; cat. no. ab207612), rabbit anti-human p62 (1:500; cat. no. ab155686), rabbit anti-human phosphorylated (p-)-PI3K (1:1,000; cat. no. ab138364), rabbit anti-human PI3K (1:1,000; cat. no. ab32089), rabbit anti-human AKT antibody (1:500; cat. no. ab8805), rabbit anti-human p-AKT antibody (1:500; cat. no. ab38449) and rabbit anti-human GAPDH antibody (1:2,500; cat.no. ab9485) were obtained from Abcam. Horseradish peroxidase (HRP)-labeled goat anti-rabbit immunoglobulin G (IgG) antibody (1:2,000; cat. no. CW0103) was purchased from Cwbio. Naringin (cat. no. HY-N0153) and 3-methyladenine (3-MA; cat. no. HY-19312) were purchased from MedChemExpress. Annexin V-fluorescein isothiocyanate (FITC) apoptosis detection kits (cat. no. KGA106) and cell cycle detection kits (cat. no. KGA511) were purchased from Keygentec. Radio-Immunoprecipitation Assay (RIPA) solution (cat. no. P0013) was obtained from Beyotime Institute of Biotechnology.

Cell culture. All cells were maintained in the RPMI-1640 medium supplemented with $10 \%$ FBS and $100 \mathrm{U} / \mathrm{ml}$ penicillin and $100 \mu \mathrm{g} / \mathrm{ml}$ streptomycin in an incubator at $37^{\circ} \mathrm{C}$ with a $5 \% \mathrm{CO}_{2}$ atmosphere. In the present study, SNU-1 cells without costunolide (Cos) treatment $(0 \mu \mathrm{g} / \mathrm{ml})$ group served as the control group.

Cell Counting Kit-8 (CKK-8) assay. Cell proliferation was analyzed using CCK-8 solution. SNU-1 and GES-1 cells (100 $\mu \mathrm{l} /$ well, $1.5 \times 10^{5}$ cells $\left./ \mathrm{ml}\right)$ were seeded in a 96 -well plate and incubated in a $\mathrm{CO}_{2}$ incubator for $24 \mathrm{~h}$ at $37^{\circ} \mathrm{C}$. After aspiration, the cells were incubated with different concentrations $(0,2.5,5,10,20,40$ and $80 \mu \mathrm{g} / \mathrm{ml})$ of Nar in FBS-free RPMI 1640 for $24 \mathrm{~h}$ and then CCK- 8 assay was used according to the manufacturer's protocol. Optical density values were measured with a microplate reader at $450 \mathrm{~nm}$.

Observation of cell morphology. The SNU-1 cells were treated with different concentrations $(0,5,10$ and $20 \mu \mathrm{g} / \mathrm{ml})$ of Nar in FBS-free RPMI 1640 for $24 \mathrm{~h}$ and observed and images captured using an inverted light microscope (magnification, x100; Olympus Corporation).

Hoechst 33258 staining. Cell apoptosis was analyzed using Hoechst 33258 staining. SNU-1 cells were seeded into 12-well plates and treated with different concentrations $(0,5,10$ and $20 \mu \mathrm{g} / \mathrm{ml}$ ) of Nar for $24 \mathrm{~h}$. The adherent cells were washed twice with phosphate-buffered saline. The cells were then stained with Hoechst 33258 for $5 \mathrm{~min}$ at room temperature and washed twice. The blue-stained nuclei was observed under the BX41 fluorescence microscope (magnification, x100; Olympus Corporation). Images were captured and used to quantitatively analyze the apoptosis of cells using Image-Pro Plus analysis software 6.0 (Media Cybernetics, Inc.).

TUNEL staining. Cell apoptosis was analyzed using TUNEL staining. SNU-1 cells were plated onto 12 -well plates for $24 \mathrm{~h}$ and treated with different concentrations $(0,5,10$ and $20 \mu \mathrm{g} / \mathrm{ml}$ ) of Nar for $24 \mathrm{~h}$. Then, apoptosis was evaluated using the TUNEL apoptosis assay kit and observed under the BX41 fluorescence microscope (magnification, x100; Olympus Corporation). Images were captured and used to quantitatively analyze the apoptosis of cells using Image-Pro Plus analysis software 6.0 (Media Cybernetics, Inc.).

Flow cytometry. Cell cycle and apoptosis were measured by flow cytometry. The cell cycle was analyzed using an Annexin V-FITC/propidium iodide (PI) apoptosis kit. The six-well plate was seeded with SNU-1 cells $\left(2.0 \mathrm{ml} /\right.$ well, $1.0 \times 10^{6}$ cells $\left./ \mathrm{ml}\right)$ cultured for $24 \mathrm{~h}$. After aspiration, the cells were incubated with $2.0 \mathrm{ml}$ of different concentrations $(0,5,10$ and $20 \mu \mathrm{g} / \mathrm{ml})$ of Nar for $24 \mathrm{~h}$, or treated with Nar before pretreatment with 3-MA, following which the collected cells were fixed with $75 \%$ ethanol at $4^{\circ} \mathrm{C}$ overnight. The cell cycle detection kit was used following the manufacturer's protocols. The cell samples were mixed with PI for $15 \mathrm{~min}$ at $37^{\circ} \mathrm{C}$ in the dark and apoptotic cells were examined with a BD FACSaria Fusion flow cytometer (BD Biosciences) and ModFit software version 3.2 (BD Biosciences). The apoptotic rate was calculated as the percentage of early and late apoptotic cells.

Western blot analysis. The changes in apoptosis-related proteins (caspase 3, Bax and $\mathrm{Bcl} 2$ ), signaling pathway-related proteins (AKT, phosphorylated (p-)AKT, PI3K and p-PI3K) and autophagy-related proteins (LC3B, Beclin-1 and p62) in SNU-1 cells were analyzed using western blot analysis. After incubation with Nar, the cells were collected and proteins were extracted on ice with RIPA lysis buffer containing protease inhibitors. Proteins were quantified with the BCA Protein Assay kit. The collected lysate samples (20 $\mu \mathrm{g} / \mathrm{well})$ were separated by sodium dodecyl sulfate-polyacrylamide gel electrophoresis (SDS-PAGE) on 12\% gels and transferred to nitrocellulose membranes blocked with $50 \mathrm{~g} / 1$ skimmed milk for $2 \mathrm{~h}$ at room temperature. Following overnight incubation 
A

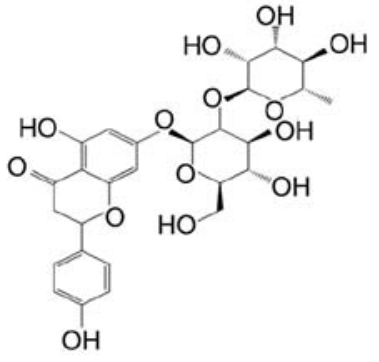

B

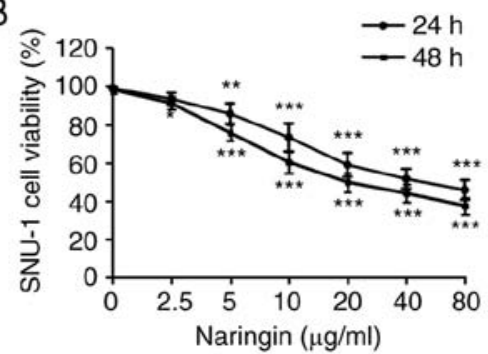

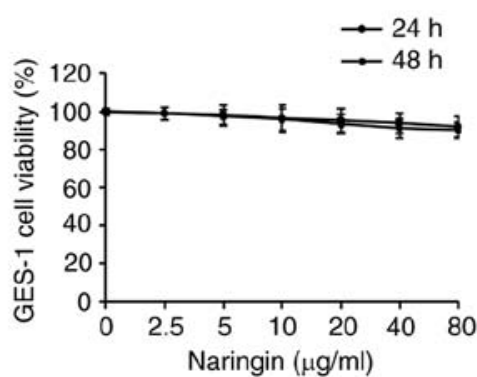

C

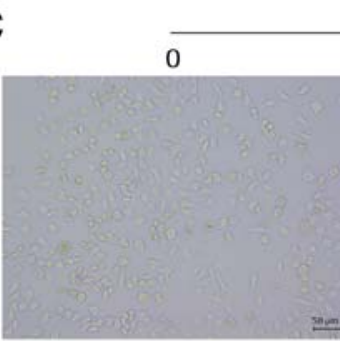

$\operatorname{Nar}(\mu \mathrm{g} / \mathrm{ml})$

5

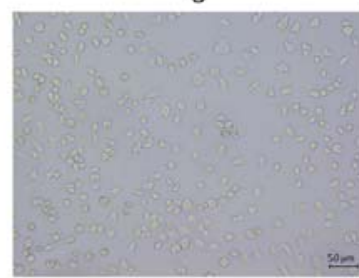

10

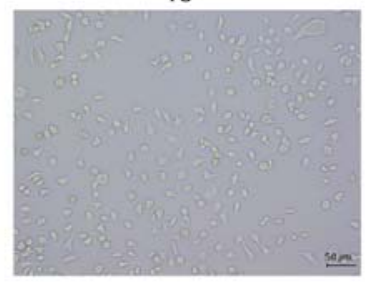

20

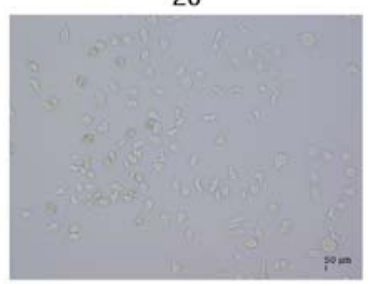

Figure 1. Naringin inhibits the proliferation of SNU-1 cells and induced cell cycle arrest. (A) Chemical structure of naringin; molecular formula: $\mathrm{C}_{27} \mathrm{H}_{32} \mathrm{O}_{14}$. (B) The viability of SNU-1 cells treated with different concentrations of costunolide for 24 and $48 \mathrm{~h}$, as detected by CCK-8 assay. ${ }^{*} \mathrm{P}<0.05,{ }^{* * *} \mathrm{P}<0.01,{ }^{* * * *} \mathrm{P}<0.001$ vs. the control group. (C) The morphology of SNU-1 cells was observed using an inverted phase contrast microscope (magnification, x200).

with the primary antibodies of caspase 3, Bax, Bcl-2, AKT, p-AKT, PI3K, p-PI3K, LC3B, Beclin-1, p62 and GAPDH at $4^{\circ} \mathrm{C}$, the membranes were incubated with an HRP-labeled goat anti-rabbit $\mathrm{IgG}$ antibody for $2 \mathrm{~h}$ at room temperature. In a darkroom, the SuperSignal ELISA Femto Substrate was added onto the membranes which were subsequently exposed to x-ray films. Protein bands were imaged using an Alpha Innotech FluorChem FC2 Imaging System (ProteinSimple). The densitometric analysis was performed using ImageJ software v1.46 (National Institutes of Health) and GAPDH expression was used to normalize the data.

Wound-healing assay. SNU-1 cells $(2.0 \mathrm{ml} / \mathrm{well}$, $1 \times 10^{6}$ cells $/ \mathrm{ml}$ ) were seeded to confluence in 6 -well plates; when the confluence of the cells reached $\sim 90 \%$ wounds were made by a $200-\mu 1$ pipette tip, then the cells were incubated in a serum-free medium with different concentrations $(0,10$, $20,40 \mu \mathrm{g} / \mathrm{ml}$ ) of Cos for $24 \mathrm{~h}$, observed and images captured using an inverted light microscope (magnification, x100; Olympus Corporation). Quantitation of wound healing assay results were analyzed by Image-Pro Plus software v 6.0 (Media Cybernetics, Inc.).

Statistical analysis. All data were shown as mean \pm standard error of mean. The intergroup deviations were evaluated using one-way analysis of variance (ANOVA) implemented in the GraphPad Prism 6.0 software. Comparison between groups was performed using one-way ANOVA followed by Tukey's test. $\mathrm{P}<0.05$ was considered to indicate a statistically significant difference.

\section{Results}

Effects of Nar on SNU-1 cell proliferation. The changes in cell proliferation were determined using CCK- 8 assay to demonstrate the effects of Nar on SNU-1 cell proliferation. As shown in Fig. 1B, Nar could significantly inhibit the proliferation of SNU-1 cells in a dose-dependent manner, but the effect of Nar on normal gastric cells (GES-1 cells) was not as sensitive as that on SNU-1 cells (Fig. 1B). The half-maximal inhibitory concentration $\left(\mathrm{IC}_{50}\right)$ for both 24 and $48 \mathrm{~h}$ was $\sim 20 \mu \mathrm{g} / \mathrm{ml}$. Therefore, the concentrations of $0,5,10$ and $20 \mu \mathrm{g} / \mathrm{ml}$ were used for subsequent in vitro assays. The results of observing the cell morphology with a phase-contrast microscope showed that Nar induced shrinkage, nuclear lysis and rupture of SNU-1 cells (Fig. 1C).

Nar induces SNU-1 cell cycle arrest. Based on the results of anti-proliferative assays, SNU-1 cells were treated with $0,5,10$ and $20 \mu \mathrm{g} / \mathrm{ml}$ Nar to reveal the effect of Nar on the cell cycle. The flow cytometry results showed that Nar could significantly induce cell cycle arrest in the $\mathrm{G}_{0} / \mathrm{G}_{1}$ phase in SNU-1 cells dose-dependently (Fig. 2).

Nar induces the apoptosis of SNU-1 cells. Hoechst 33258 and TUNEL staining demonstrated that the rate of apoptosis increased with an increase in Nar concentration (Fig. 3A and B). The flow cytometry results showed that Nar could dose-dependently induce the apoptosis of SNU-1 cells (Fig. 4A). Western blot analysis results also demonstrated that Nar upregulated the expression of caspase 3 and Bax, but downregulated the expression of $\mathrm{Bcl}-2$ in a dose-dependent manner (Fig. 4B).

Nar induces apoptosis of SNU-1 cells via inhibiting the PI3K/AKT pathway. The changes in PI3K/AKT pathway-related proteins treated with different concentrations of Nar were detected using western blot analysis. The results showed that the ratios p-PI3K/PI3K and p-AKT/AKT were downregulated in a dose-dependent manner (Fig. 5A). After 

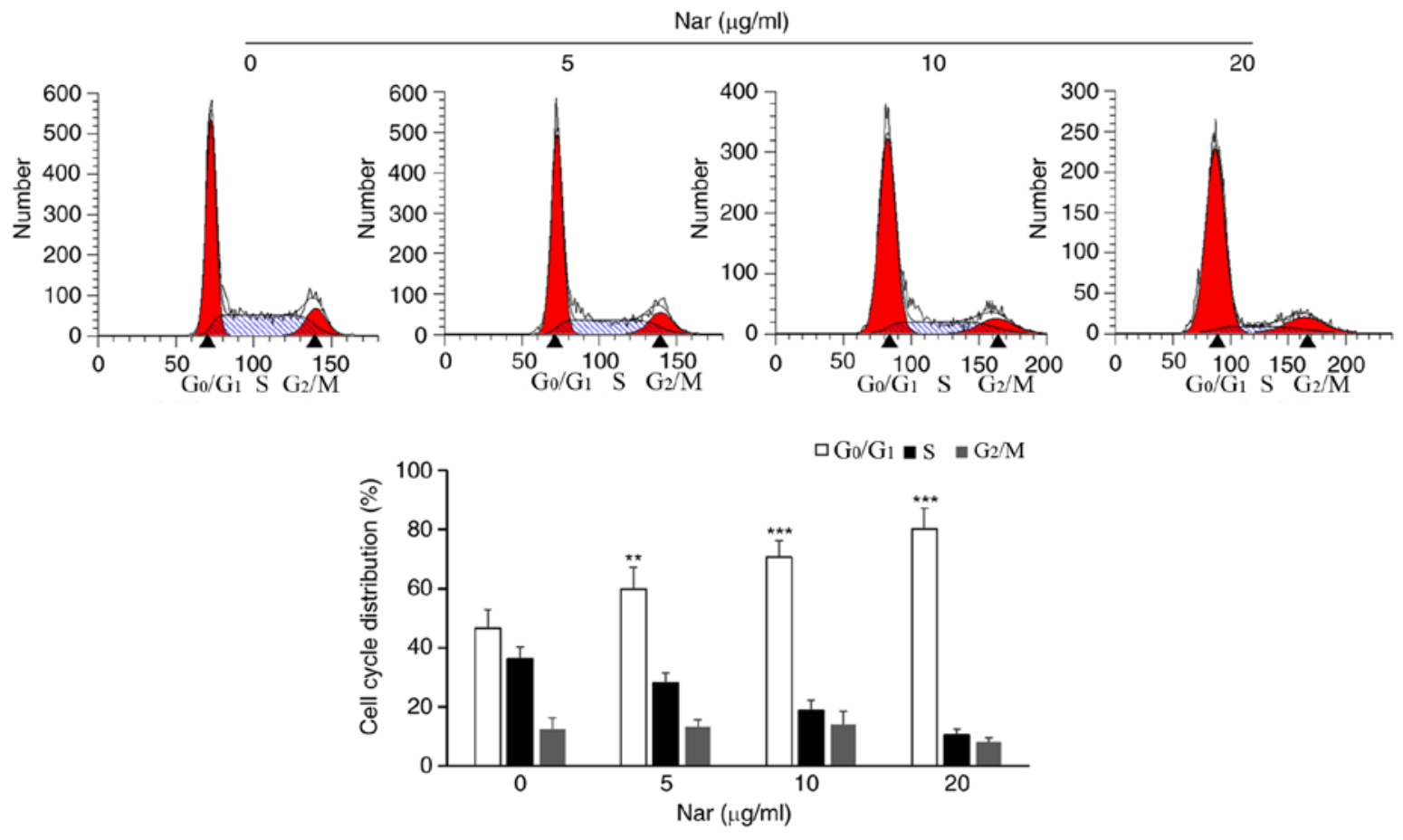

Figure 2. Effects of Nar on the SNU-1 cell cycle were determined by flow cytometry. ${ }^{* *} \mathrm{P}<0.01,{ }^{* * *} \mathrm{P}<0.001$ vs. the control group. Nar, naringin.

A $\operatorname{Nar}(\mu \mathrm{g} / \mathrm{ml})$
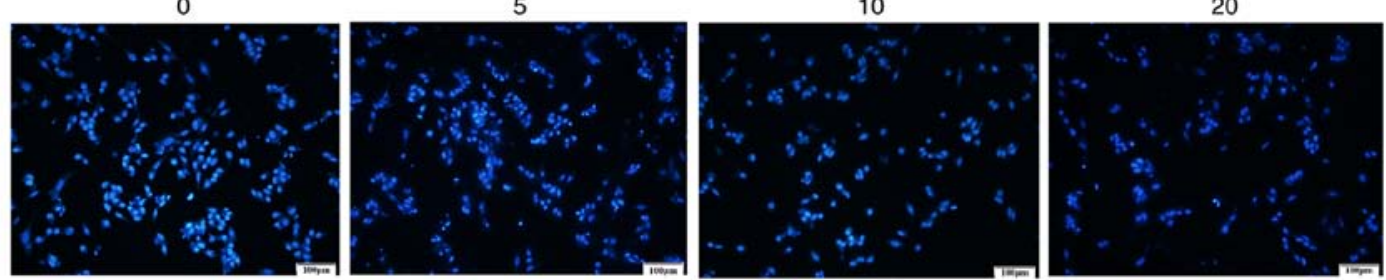

B

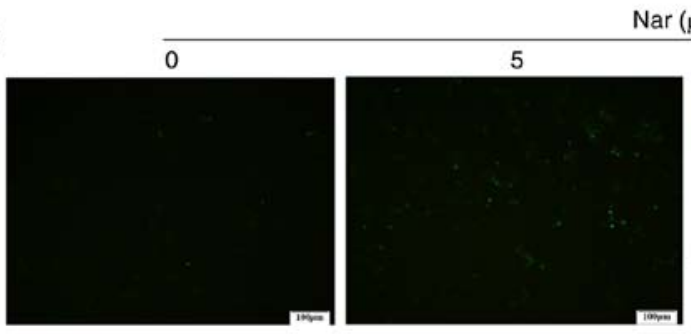

$\operatorname{Nar}(\mu \mathrm{g} / \mathrm{ml})$
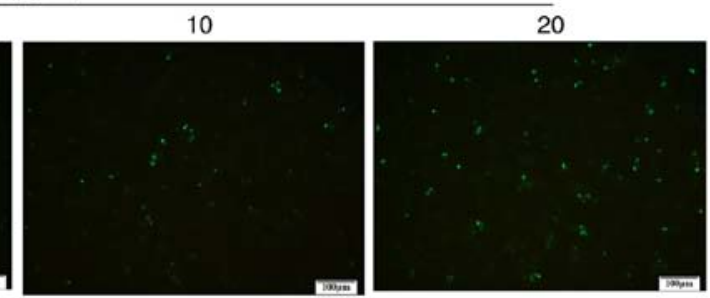

Figure 3. Nar induces apoptosis of SNU-1 cells. (A) Hoechst 33258 staining (magnification, x100). (B) TUNEL staining (magnification, x100). Nar, naringin.

pretreatment with 3-MA, an inhibitor of PI3K, the ratios of p-PI3K/PI3K and p-AKT/AKT in cells co-treated with 3-MA and Nar were markedly downregulated compared with those in cells treated with Nar or 3-MA alone (Fig. 5B).

Nar induces apoptosis via activating autophagy in SNU-1 cells. Transmission electron microscopy results showed the formation of autophagic vacuoles in SNU-1 cells following treatment with Nar (Fig. 6A). Western blot analysis results showed that Nar could promote the expression of Beclin-1, increase the LC3BII/LC3BI ratio and inhibit the expression of p62 (Fig. 6B). SNU-1 cells were treated with $10 \mu \mathrm{g} / \mathrm{ml}$ Nar for $24 \mathrm{~h}$ before incubating with $4 \mathrm{mmol} / \mathrm{l}$ 3-MA (an autophagy inhibitor) for $1 \mathrm{~h}$ and the apoptosis were measured by flow cytometry. The results showed that Nar-induced apoptosis was significantly attenuated in the 3-MA- and Nar-co-treated group compared with the Nar-treated group (Fig. 7A). Western blot analysis results also showed that the Beclin-1 expression level and the LC3BII/LC3BI ratio were markedly downregulated and the expression of p62 was upregulated in 3-MA-treated SNU-1 cells. However, when cells were co-stimulated with 3-MA and Nar, Beclin-1 expression level and LC3BII/LC3BI ratio significantly increased and the p62 degradation was rescued compared with those in cells treated with 3-MA alone (Fig. 7B).

Nar inhibits migration of SNU-1 cells. Wound-healing assay results demonstrated that Nar inhibited the migration of SNU-1 cells in a dose-dependent manner (Fig. 8). 
A

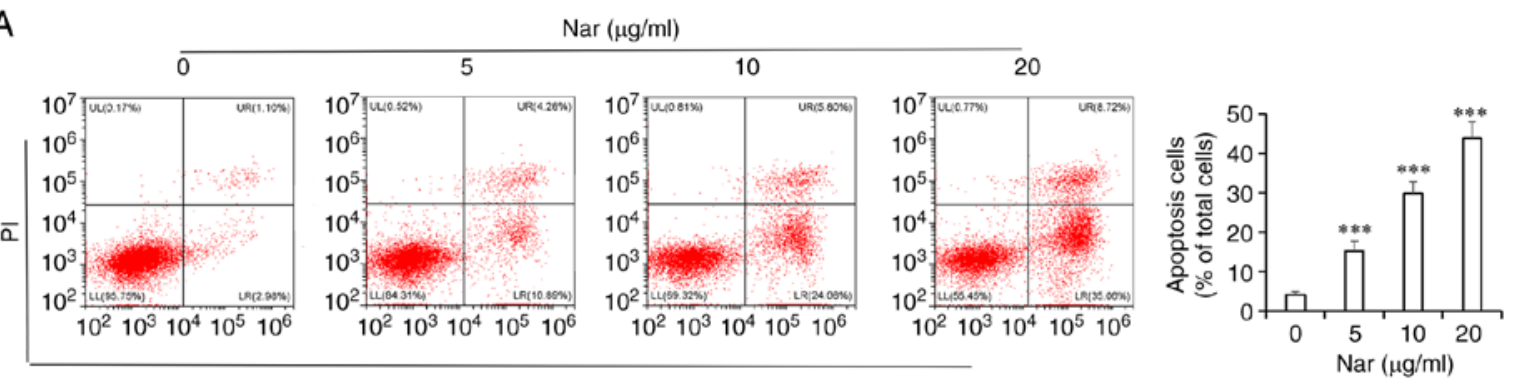

Annexin V

B

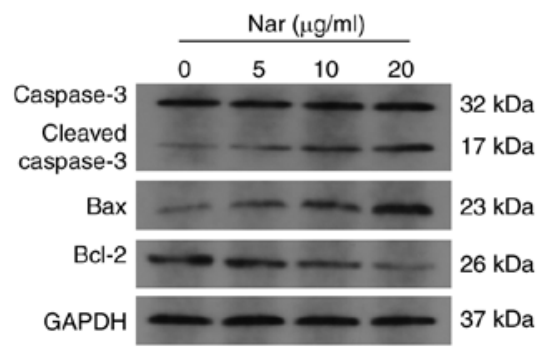

$\square$ Cle caspase-3/caspase-3 $₫ \mathrm{Bax} / \mathrm{GAPDH} \equiv \mathrm{Bcl}-2 / \mathrm{GAPDH}$

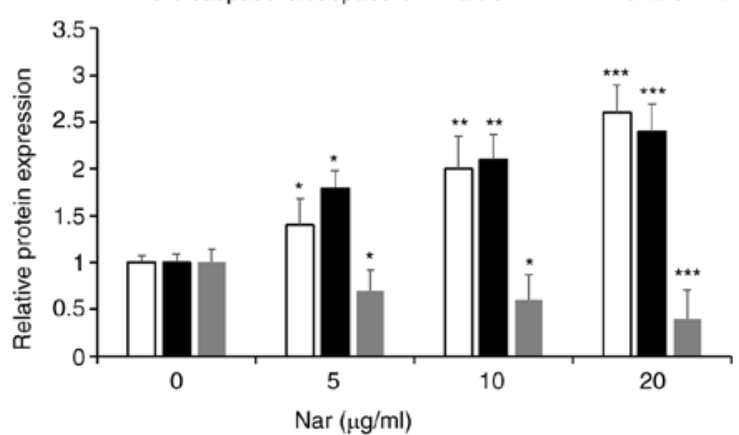

Figure 4. SNU-1 cell apoptosis as determined by flow cytometry and western blot analysis. (A) The apoptosis of Nar induced in SNU-1 cells was analyzed by flow cytometry. (B) The apoptosis of Nar induced in SNU-1 cells was analyzed by western blot analysis. GAPDH expression was used to normalize the data. ${ }^{*} \mathrm{P}<0.05,{ }^{* * *} \mathrm{P}<0.01,{ }^{* * *} \mathrm{P}<0.001$ vs. the control group. Nar, naringin.

A

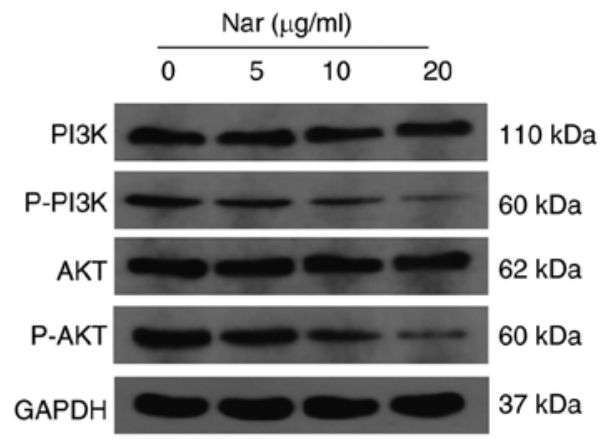

B

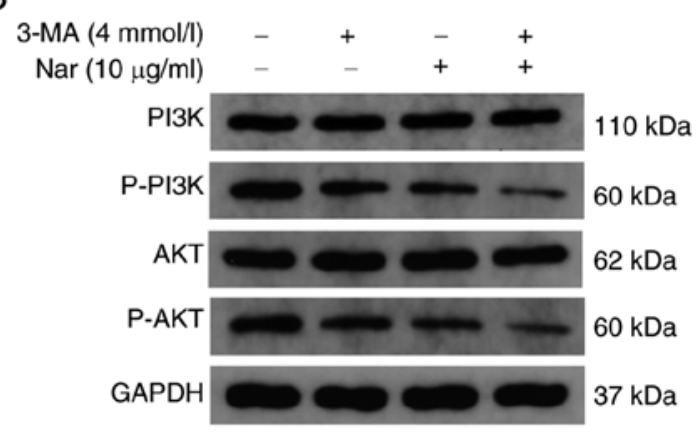

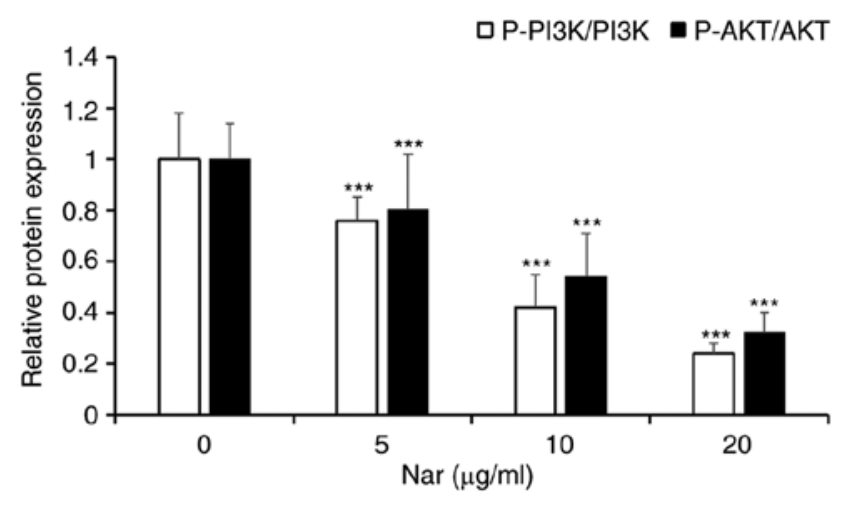

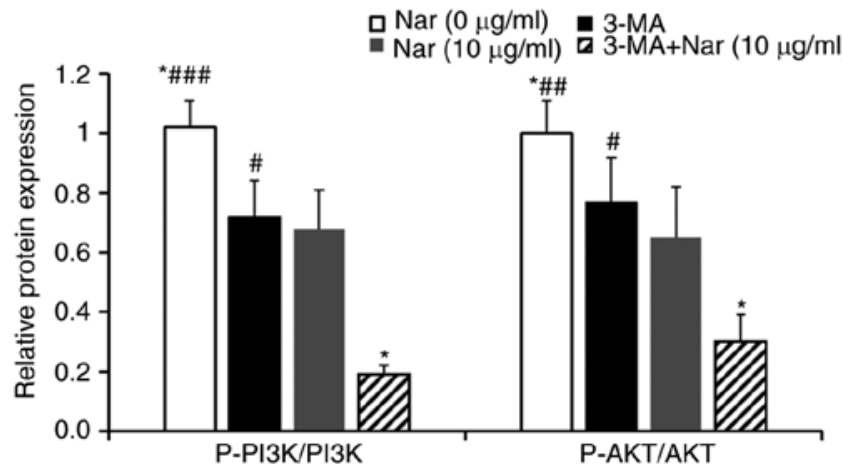

Figure 5. Nar induces apoptosis and autophagy of SNU-1 cells by inhibiting the PI3K/AKT signaling pathway. (A) Changes in cellular PI3K, p-PI3K, AKT and p-AKT levels were determined by western blot analysis. GAPDH expression was used to normalize the data. (B) Changes in PI3K, p-PI3K, AKT and p-AKT levels in SNU-1 cells following Nar $(10 \mu \mathrm{g} / \mathrm{ml}), 3-\mathrm{MA}$ and $\mathrm{Nar}(10 \mu \mathrm{g} / \mathrm{ml})$ plus 3-MA treatment. GAPDH expression was used to normalize the data. "P<0.05,

${ }^{* * * *} \mathrm{P}<0.001$ vs. $\operatorname{Nar}(10 \mu \mathrm{g} / \mathrm{ml})$ group; ${ }^{\#} \mathrm{P}<0.05,{ }^{\# \#} \mathrm{P}<0.01,{ }^{\# \# \#} \mathrm{P}<0.001$ vs. Nar $(10 \mu \mathrm{g} / \mathrm{ml})$ plus $3-\mathrm{MA}$ group. Nar, naringin; $\mathrm{p}-$, phosphorylated.

\section{Discussion}

Gastric cancer is one of the commonest and most malignant tumors in the digestive system (19). Although the treatment of gastric cancer has improved to a certain level with the advancement of medical technology, the survival rate of patients with gastric cancer remains poor. Therefore, seeking more effective adjuvant treatment to improve the therapeutic 
A

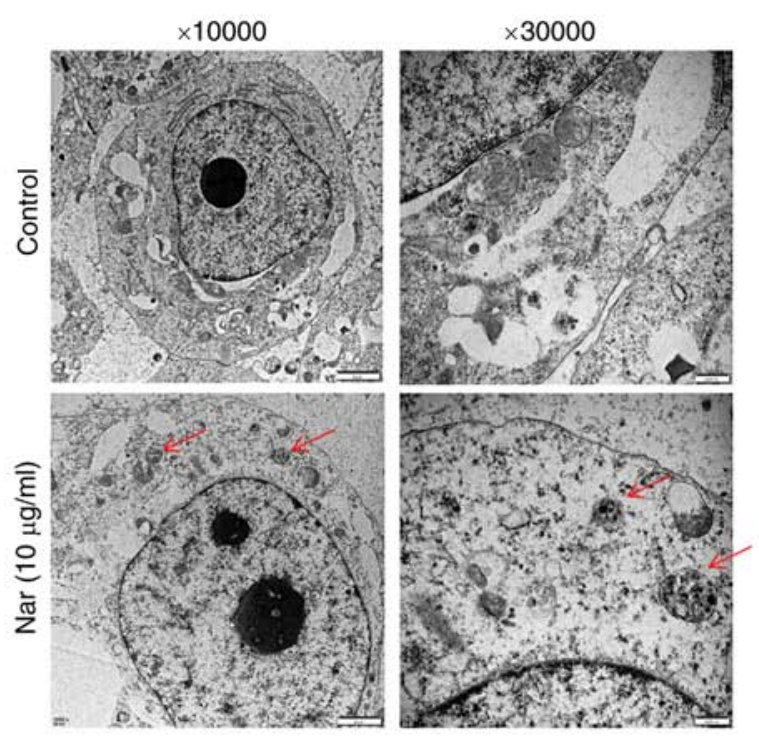

B
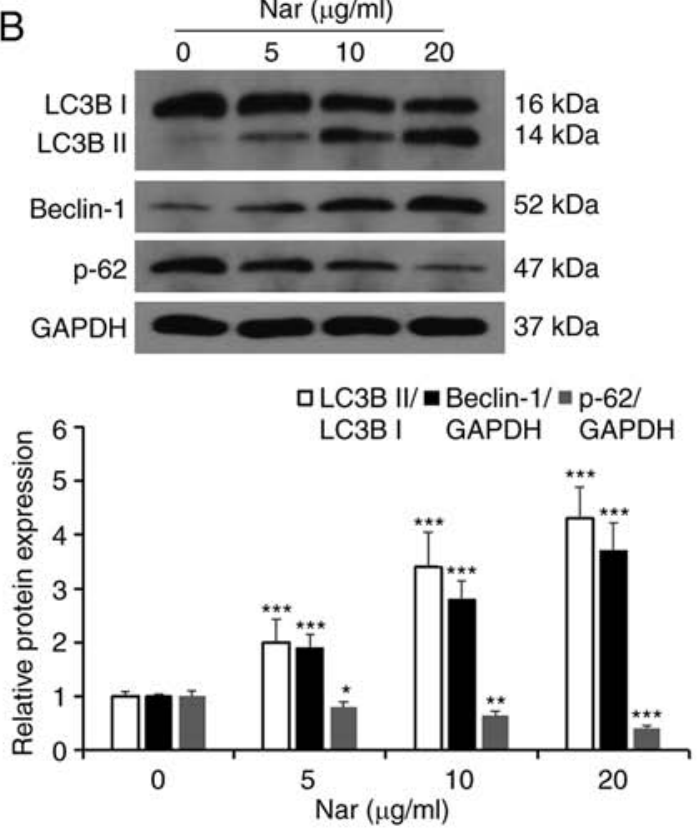

Figure 6. Nar induces autophagy in SNU-1 cells. (A) The autophagic microstructures were observed by transmission electron microscopy [red arrow: Autophagic vacuole (autophagosome or autophagosome)]. (B) The levels of cell autophagy-associated proteins were determined by western blot analysis. GAPDH expression was used to normalize the data. ${ }^{*} \mathrm{P}<0.05,{ }^{* *} \mathrm{P}<0.01,{ }^{* * *} \mathrm{P}<0.001$ vs. the control group. Nar, naringin; LC3B, microtubule-associated protein 1 light chain $3 \beta$.

\section{A}

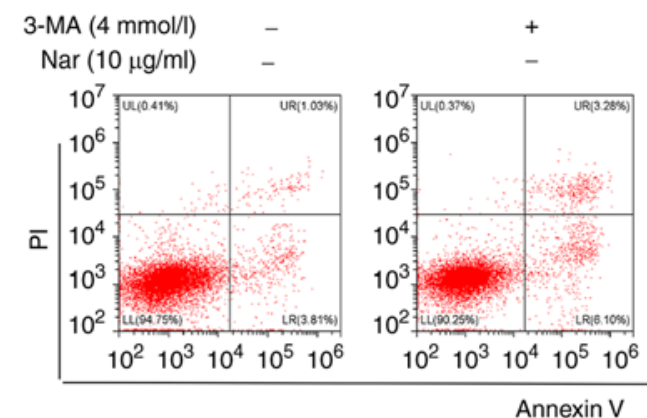

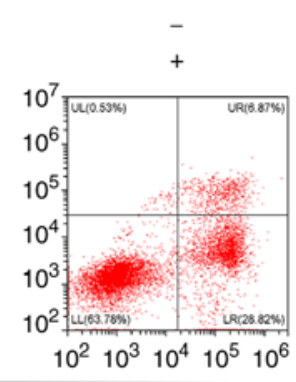

$10^{2} 10^{3} 10^{4} 10^{5} 10^{6}$

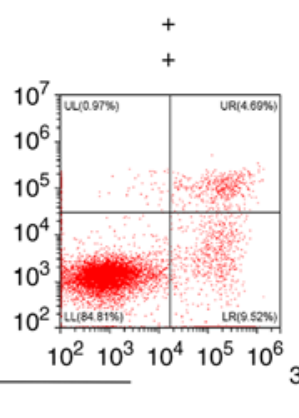

3-MA $(4 \mathrm{mmol} / \mathrm{l})$

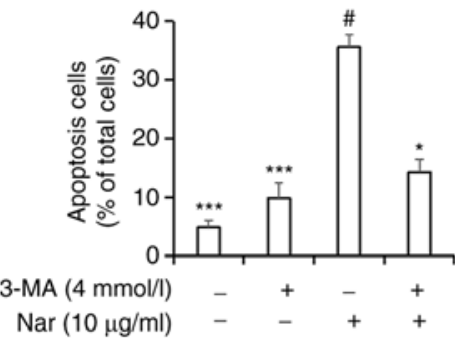

B

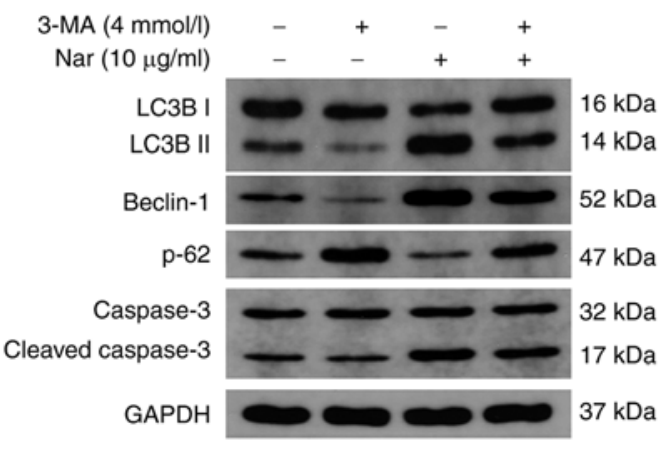

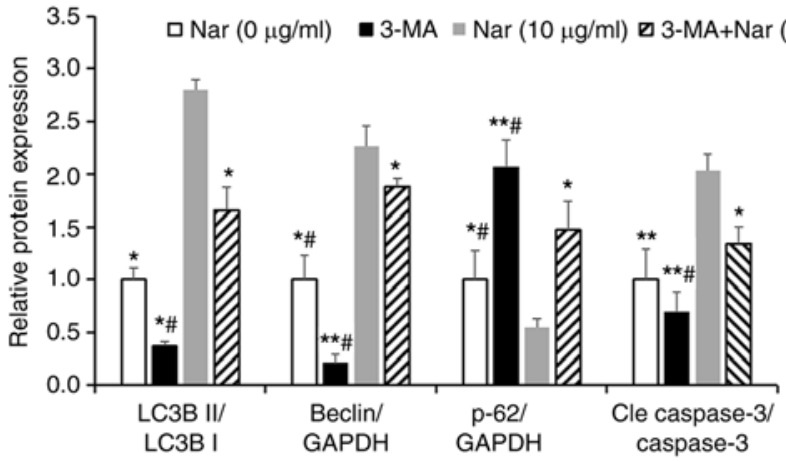

Figure 7. Changes in SNU-1 cell apoptosis after inhibiting autophagy with 3-MA. (A) Changes in the apoptosis of SNU-1 cells after Nar (10 $\mu \mathrm{g} / \mathrm{ml}), 3-\mathrm{MA}$ and $\operatorname{Nar}(10 \mu \mathrm{g} / \mathrm{ml})$ plus 3-MA treatment were analyzed by flow cytometry analysis. (B) Changes in autophagy-related proteins and caspase 3 of SNU-1 cells after $\operatorname{Nar}(10 \mu \mathrm{g} / \mathrm{ml}), 3-\mathrm{MA}$ and $\mathrm{Nar}(10 \mu \mathrm{g} / \mathrm{ml})$ plus 3-MA treatment were analyzed by western blot analysis. GAPDH expression was used to normalize the data. ${ }^{*} \mathrm{P}<0.05,{ }^{* *} \mathrm{P}<0.01,{ }^{* * *} \mathrm{P}<0.001$ vs. Nar $(10 \mu \mathrm{g} / \mathrm{ml})$ group; ${ }^{*} \mathrm{P}<0.05$ vs. Nar $(10 \mu \mathrm{g} / \mathrm{ml})$ plus 3-MA group. Nar, naringin; LC3B, microtubule-associated protein 1 light chain $3 \beta ;$ p-, phosphorylated.

effect on GC is urgently required for patients undergoing surgery and chemotherapy. Some studies have shown that $\sim 60 \%$ of cancer patients in the United States take high-dose complex antioxidant nutrients while undergoing conventional 

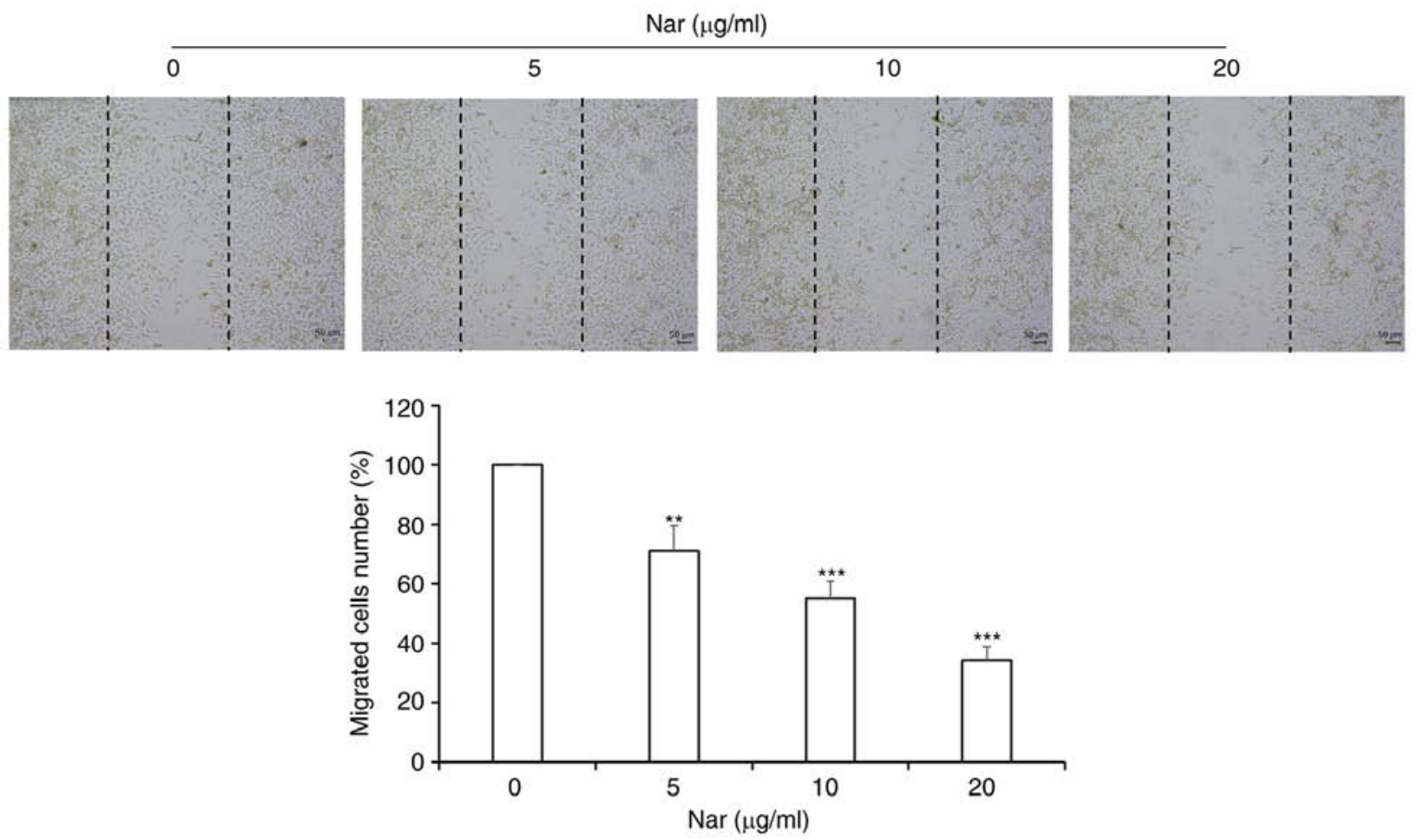

Figure 8. Nar inhibits migration of SNU-1 cells (magnification, $\mathrm{x} 100)$ ) ${ }^{* *} \mathrm{P}<0.01,{ }^{* * *} \mathrm{P}<0.001$ vs. the control group. Nar, naringin.

treatment to improve the effect of conventional anti-cancer treatment and reduce the side effects of radiotherapy and chemotherapy $(20,21)$. Oxidative nutrients (antioxidants) refer to a class of nutrients that have antioxidant capacity, inhibit the generation of free radicals, accelerate the elimination of free radicals and inhibit the oxidative damage of biological macromolecules caused by free radicals (20). Green vegetables such as cauliflower are rich sources of antioxidant nutrients, such as vitamin $\mathrm{A}$, vitamin $\mathrm{C}$, vitamin $\mathrm{E}$ and their derivatives, while citrus fruits are rich in flavonoids, isoflavones and saponins (9). At present, a large number of cell culture experiments, animal experiments and some clinical trials have confirmed that compound antioxidant nutrients have positive effects in anti-cancer treatment (20). In addition, studies have found that a number of plant-derived molecules can exert their anti-cancer effects by targeting specific signaling pathways $(22,23)$. Therefore, extracting pure natural drugs from plants to develop more effective and nontoxic anti-cancer agents is an ideal and promising avenue. The Nar used in the present study is a dihydroflavonoid compound extracted from citrus fruits. Its biologically active substances are not only are plentiful in content but various, mainly including flavonoids, limonoids, carotenoids, coumarins, essential oils, dietary fiber and pectin (24). Nar has various biological activities, such as anti-inflammatory, anti-viral, anti-cancer, anti-mutation, anti-allergic, anti-ulcer, analgesic and antihypertensive. Gastric cancer has a number of risk factors, including gastric ulcer, atrophic gastritis and Helicobacter pylori infection. Nar can suppress these risk factors, which is particularly important in the prevention and adjuvant treatment of gastric cancer. In recent years, some anti-cancer active ingredients in Nar have become research targets in the food and medical fields $(10,25)$. They can inhibit the growth of cancer cells via different molecular mechanisms, such as triggering cell cycle arrest, apoptosis, necrosis and autophagy (26). Studies have found that Nar initiates the release of TNF by inducing lipopolysaccharides, reduces the incidence of liver cancer, induces cancer cell apoptosis and inhibits oncogene expression through anti-oxidative and anti-free radical effects $(27,28)$. However, the effect of Nar on gastric cancer SNU-1 cells and the related mechanism have been seldom studied. The present study demonstrated that Nar inhibited SNU-1 cell proliferation in a dose- and time-dependent manner. The inhibition of cell proliferation is considered to be specific to gastric cancer because Nar has no obvious inhibitory effect on normal gastric mucosal GES-1 cells, indicating that it has no cytotoxicity on human normal gastric cells. In addition, the present study found that Nar had an anti-proliferative effect on SNU-1 cells at low concentrations, as observed under an inverted microscope. This indicated that if Nar is supplemented continuously for a period of time, it would be effective even at lower concentrations. Nar has an anti-cancer effect on esophageal cancer stem cell xenotransplanted tumor mouse models without altering the body and liver weight and the combination of Nar and doxorubicin can reduce the side effects of doxorubicin (29). Nar is both effective and safe as an anti-cancer drug (30). The present study found that Nar arrested SNU-1 cells in the $G_{0} / G_{1}$ phase, promoting apoptosis in a dose-dependent manner. Further mechanistic studies demonstrated that Nar significantly blocked the PI3K/AKT signaling pathway and activated autophagy. 3-MA pretreatment significantly attenuated Nar-induced apoptosis. The results suggested the potential relevance of consuming Nar-rich foods or nutrients in reducing the development of gastric cancer.

Tumors are characterized by abnormal cell proliferation. Various anti-tumor drugs induce tumor cell cycle arrest and 
apoptosis, thereby inhibiting the abnormal proliferation of tumor cells and exerting anti-cancer activities (31-33). Nar can induce cell cycle arrest and apoptosis in human breast cancer (34). In cervical cancer cells, Nar induces $\mathrm{G}_{0} / \mathrm{G}_{1}$ phase arrest and activated endoplasmic reticulum-mediated apoptosis (35). It also induces $\mathrm{G}_{0} / \mathrm{G}_{1}$ phase arrest and apoptosis in human osteosarcoma MG63 and U2OS cells (36). The results confirmed that Nar significantly inhibited SNU-1 cells and induced $G_{0} / G_{1}$ phase arrest and apoptosis in a concentration-dependent manner. In addition, the results confirmed that Nar promoted the generation of cleaved caspase 3 in SNU-1 cells. The aforementioned results indicated that Nar inhibited SNU-1 cell proliferation by promoting the $G_{0} / G_{1}$ phase arrest and apoptosis. This was consistent with the results of previous studies showing that flavonoids, such as apigenin, luteolin and myricetin, induced exogenous apoptosis in different cancer cell lines (37-39).

The PI3K/AKT pathway is a classic signaling pathway involved in regulating a variety of cellular processes, including proliferation, migration, differentiation and apoptosis (40). Previous studies have identified anti-cancer drugs inducing apoptosis by blocking the PI3K/AKT signaling pathway $(41,42)$. In colorectal cancer, Nar inhibits cell growth and induces apoptosis via blocking the PI3K/AKT signaling pathway (15). By targeting this pathway, Nar inhibits the proliferation of thyroid cancer cells and induces apoptosis (43). The mechanism may be that activated Akt can promote the Ser184 phosphorylation of Bax, which can negatively regulate the pro-apoptotic function and could also inactivate caspase-9 Ser196 phosphorylation and inhibit apoptosis $(32,33)$. The results of the present study showed that Nar could significantly induce SNU-1 cell apoptosis by inhibiting the PI3K/AKT signaling pathway in SNU-1 cells.

Autophagy is a lysosomal degradation pathway of the cell. It is characterized by an increase in the number of acidic vesicle organelles associated with autophagosomes, which is often dysregulated in cancer as another important form of programmed cell death (44). Autophagy can both promote cell death and inhibit cell death. In tumor cells, the effect of autophagy often depends on the cell type (45). Previous studies have confirmed autophagy as an important signal downstream of the PI3K/AKT pathway; it is involved in drug-induced cancer cell apoptosis $(46,47)$. Recent studies have confirmed that Nar activates autophagy by inhibiting PI3K/AKT signal, thereby inhibiting the growth of gastric cancer cells (48). The results of the present study confirmed that Nar significantly activated autophagy, featured by the expression of autophagy-related proteins LC3BII and Beclin 1 increased, while the expression of p62 decreased in a dose-dependent manner. This was inconsistent with reports that apigenin (which is a flavonoid) could induce autophagy and promote the increase in p62 expression. The p62 protein is located on the autophagosome by LC3 binding and it is degraded by autophagy (49). The overexpression of p62 can activate caspase 8 and promote cell apoptosis, which is related to the ubiquitin-associated domain at the $\mathrm{C}$ terminal (50). This indicates that besides being a marker of autophagy activation, p62 protein also served as an important regulator of apoptosis. Inhibiting autophagy significantly attenuated the generation of caspase 3 spliceosome induced by Nar. Based on these results, it was confirmed that PI3K/AKT signaling and autophagy were involved in the process of Nar-induced apoptosis in SNU-1 cells. Finally, the anti-gastric cancer metastatic effect of Nar was investigated using a wound healing test. The drug inhibited the migration of SNU-1 cells, further confirming that Nar had an anti-gastric cancer effect. However, its mechanism and whether Nar has the potential to overcome drug resistance in gastric cancer in the same manner as S-adenosyl-1-methionine needs to be studied in follow-up experiments (50). In addition, the experiments were performed only in a specific cancer cell line, SNU-1. At least one key finding should be reproduced in a different cancer cell line. Therefore, the use of one cell line as a limitation of the present study will be improved in the future studies. These future studies intend to use single-cell sequencing to screen out the targets of Nar acting on gastric cancer cells and further reveal its mechanism of action. In addition, the combination of Nar and other Chinese medicine monomers is being currently studied, to find the best combination for the treatment of gastric cancer.

In summary, Nar significantly inhibited the growth of SNU-1 cells, inducing $\mathrm{G}_{0} / \mathrm{G}_{1}$ phase arrest and apoptosis. Moreover, it induced SNU-1 cell apoptosis by inhibiting the PI3K/AKT signaling and activating autophagy. The present study was based on the potential application of Nar as a protective nutrient and chemopreventive and therapeutic molecule, confirming that Nar was a potential drug for the treatment of gastric cancer.

Our research group has conducted research on the anti-tumor mechanisms of luteolin, costanolactone and oleandrin. The combined effect and mechanism of several drugs will be further explored in detail. The findings are expected to lay the foundation for the development of anti-cancer plant nutrition sources in food science.

\section{Acknowledgements}

Not applicable.

\section{Funding}

The present study was supported by the Shaanxi Science and Technology Innovation Team (grant no. 2017KCT-28), the Shaanxi Province Key R\&D Project (grant no. 2019ZDLSF02-09-01) and the National Natural Science Foundation of China (grant no. 81900686).

\section{Availability of data and materials}

All data generated or analyzed in the present study are included in this published article.

\section{Authors' contributions}

$\mathrm{CX}, \mathrm{XH}, \mathrm{JW}$ and $\mathrm{XD}$ conceived and designed the experiments. $\mathrm{CX}, \mathrm{XH}, \mathrm{YH}, \mathrm{XL}$ and $\mathrm{MW}$ performed the experiments. CX, $\mathrm{XH}$ and $\mathrm{JW}$ analyzed the data. CX, JW and XD performed data interpretation and made critical manuscript revisions. CX and $\mathrm{XH}$ wrote the manuscript and confirmed the authenticity of all the raw data. All authors reviewed and approved the final manuscript. 


\section{Ethics approval and consent to participate}

Not applicable.

\section{Patient consent for publication}

Not applicable.

\section{Competing interests}

The authors declare that they have no competing interests.

\section{References}

1. Bray F, Ferlay J, Soerjomataram I, Siegel RL, Torre LA and Jemal A: Global cancer statistics 2018: GLOBOCAN estimates of incidence and mortality worldwide for 36 cancers in 185 countries. CA Cancer J Clin 68: 394-424, 2018.

2. Strand MS, Lockhart AC and Fields RC: Genetics of gastric cancer. Surg Clin North Am 97: 345-370, 2017.

3. Hamashima C: Current issues and future perspectives of gastric cancer screening. World J Gastroenterol 20: 13767-13774, 2014.

4. Zong L, Abe M, Seto Y and Ji J: The challenge of screening for early gastric cancer in China. Lancet 388: 2606, 2016.

5. Chen W, Zheng R, Baade PD, Zhang S, Zeng H, Bray F, Jemal A, $\mathrm{Yu}$ XQ and He J: Cancer statistics in China, 2015. CA Cancer J Clin 66: 115-132, 2016.

6. Roder DM: The epidemiology of gastric cancer. Gastric Cancer 5 (Suppl 1): S5-S11, 2002.

7. Ang TL and Fock KM: Clinical epidemiology of gastric cancer. Singapore Med J 55: 621-628, 2014.

8. Kuo YT, Chang TT, Muo CH, Wu MY, Sun MF, Yeh CC and Yen HR: Use of complementary traditional Chinese medicines by adult cancer patients in Taiwan: A nationwide population-based study. Integr Cancer Ther 17: 531-541, 2018.

9. Singh N, Bansal Y, Bhandari R, Marwaha L, Singh R, Chopra K and Kuhad A: Naringin reverses neurobehavioral and biochemical alterations in intracerebroventricular collagenase-induced intracerebral hemorrhage in rats. Pharmacology 100: 172-187, 2017.

10. Chen R, Qi QL, Wang MT and Li QY: Therapeutic potential of naringin: An overview. Pharm Biol 54: 3203-3210, 2016.

11. Bharti S, Rani N, Krishnamurthy B and Arya DS: Preclinical evidence for the pharmacological actions of naringin: A review. Planta Med 80: 437-451, 2014.

12. Jeon SM, Bok SH, Jang MK, Kim YH, Nam KT, Jeong TS, Park YB and Choi MS: Comparison of antioxidant effects of naringin and probucol in cholesterol-fed rabbits. Clin Chim Acta 317: 181-190, 2002.

13. Jagetia GC and Reddy TK: Modulation of radiation-induced alteration in the antioxidant status of mice by naringin. Life Sci 77: 780-794, 2005.

14. Rajadurai M and Stanely Mainzen Prince P: Preventive effect of naringin on lipid peroxides and antioxidants in isoproterenol-induced cardiotoxicity in Wistar rats: Biochemical and histopathological evidences. Toxicology 228: 259-268, 2006.

15. Cheng H, Jiang X, Zhang Q, Ma J, Cheng R, Yong H, Shi H, Zhou X, Ge L and Gao G: Naringin inhibits colorectal cancer cell growth by repressing the PI3K/AKT/mTOR signaling pathway. Exp Ther Med 19: 3798-3804, 2020.

16. Ramesh E and Alshatwi AA: Naringin induces death receptor and mitochondria-mediated apoptosis in human cervical cancer ( $\mathrm{SiHa}$ ) cells. Food Chem Toxicol 51: 97-105, 2013.

17. Cai L, Wu H, Tu C, Wen X and Zhou B: Naringin inhibits ovarian tumor growth by promoting apoptosis: An in vivo study. Oncol Lett 16: 59-64, 2018.

18. Banjerdpongchai R, Wudtiwai B and Khawon P: Induction of human hepatocellular carcinoma HepG2 cell apoptosis by naringin. Asian Pac J Cancer Prev 17: 3289-3294, 2016.

19. Smyth EC, Nilsson M, Grabsch HI, van Grieken NC and Lordick F: Gastric cancer. Lancet 396: 635-648, 2020.

20. Ilghami R, Barzegari A, Mashayekhi MR, Letourneur D, Crepin $M$ and Pavon-Djavid G: The conundrum of dietary antioxidants in cancer chemotherapy. Nutr Rev 78: 65-76, 2020 .
21. McDermott JH: Antioxidant nutrients: Current dietary recommendations and research update. J Am Pharm Assoc (Wash) 40: 785-799, 2000

22. Nijveldt RJ, van Nood E, van Hoorn DE, Boelens PG, van Norren K and van Leeuwen PA: Flavonoids: A review of probable mechanisms of action and potential applications. Am J Clin Nutr 74: 418-425, 2001.

23. Courdavault V, O'Connor SE, Oudin A, Besseau S and Papon N: Towards the microbial production of plant-derived anticancer drugs. Trends Cancer 6: 444-448, 2020.

24. Wang X, Ouyang Y, Liu J, Zhu M, Zhao G, Bao W and Hu FB: Fruit and vegetable consumption and mortality from all causes, cardiovascular disease, and cancer: Systematic review and dose-response meta-analysis of prospective cohort studies. BMJ 349: g4490, 2014.

25. Alam MA, Subhan N, Rahman MM, Uddin SJ, Reza HM and Sarker SD: Effect of citrus flavonoids, naringin and naringenin, on metabolic syndrome and their mechanisms of action. Adv Nutr 5: 404-417, 2014

26. Mani JS, Johnson JB, Hosking H, Ashwath N, Walsh KB, Neilsen PM, Broszczak DA and Naiker M: Antioxidative and therapeutic potential of selected Australian plants: A review. J Ethnopharmacol 268: 113580, 2021.

27. Blankson H, Grotterød EM and Seglen PO: Prevention of toxin-induced cytoskeletal disruption and apoptotic liver cell death by the grapefruit flavonoid, naringin. Cell Death Differ 7: 739-746, 2000

28. Kawaguchi K, Kikuchi S, Hasegawa H, Maruyama H, Morita $H$ and Kumazawa Y: Suppression of lipopolysaccharide-induced tumor necrosis factor-release and liver injury in mice by naringin. Eur J Pharmacol 368: 245-250, 1999.

29. Tajaldini M, Samadi F, Khosravi A, Ghasemnejad A and Asadi J: Protective and anticancer effects of orange peel extract and naringin in doxorubicin treated esophageal cancer stem cell xenograft tumor mouse model. Biomed Pharmacother 121: 109594, 2020.

30. Tarun EI, Kurchenko VP and Metelitsa DI: Flavonoids as effective protectors of urease from ultrasonic inactivation in solutions. Bioorg Khim 32: 391-398, 2006 (In Russian).

31. Liu Y, Kang X, Niu G, He S, Zhang T, Bai Y, Li Y, Hao H, Chen C, Shou Z and Li B: Shikonin induces apoptosis and prosurvival autophagy in human melanoma A375 cells via ROS-mediated ER stress and p38 pathways. Artif Cells Nanomed Biotechnol 47: 626-635, 2019

32. Kang X, Wang H, Li Y, Xiao Y, Zhao L, Zhang T, Zhou S, Zhou X, Li Y, Shou Z, et al: Alantolactone induces apoptosis through ROS-mediated AKT pathway and inhibition of PINK1-mediated mitophagy in human HepG2 cells. Artif Cells Nanomed Biotechnol 47: 1961-1970, 2019.

33. Qiu C, Zhang T, Zhang W, Zhou L, Yu B, Wang W, Yang Z, Liu Z, Zou P and Liang G: Licochalcone a inhibits the proliferation of human lung cancer cell lines A549 and $\mathrm{H} 460$ by inducing G2/M cell cycle arrest and ER stress. Int J Mol Sci 18: 1761, 2017.

34. Kabala-Dzik A, Rzepecka-Stojko A, Kubina R, Iriti M, Wojtyczka RD, Buszman E and Stojko J: Flavonoids, bioactive components of propolis, exhibit cytotoxic activity and induce cell cycle arrest and apoptosis in human breast cancer cells MDA-MB-231 and MCF-7-a comparative study. Cell Mol Biol (Noisy-le-grand) 64: 1-10, 2018.

35. Lin R, Hu X, Chen S, Shi Q and Chen H: Naringin induces endoplasmic reticulum stress-mediated apoptosis, inhibits $\beta$-catenin pathway and arrests cell cycle in cervical cancer cells. Acta Biochim Pol 67: 181-188, 2020.

36. Ming H, Chuang Q, Jiashi W, Bin L, Guangbin W and Xianglu J: Naringin targets Zeb1 to suppress osteosarcoma cell proliferation and metastasis. Aging (Albany NY) 10: 4141-4151,2018.

37. Sang Eun H, Seong Min K, Ho Jeong L, Vetrivel P, Venkatarame Gowda Saralamma V, Jeong Doo H, Eun Hee K, Sang Joon L and Gon Sup K: Scutellarein induces Fas-mediated extrinsic apoptosis and G2/M cell cycle arrest in Hep3B hepatocellular carcinoma cells. Nutrients 11: 263, 2019

38. Zhang Y, Xu X, Li W, Miao H, Huang S, Zhou Y, Sun Y, Li Z, Guo Q and Zhao L: Activation of endoplasmic reticulum stress and the extrinsic apoptotic pathway in human lung cancer cells by the new synthetic flavonoid, LZ-205. Oncotarget 7: 87257-87270, 2016.

39. Tavsan $Z$ and Kayali HA: Flavonoids showed anticancer effects on the ovarian cancer cells: Involvement of reactive oxygen species, apoptosis, cell cycle and invasion. Biomed Pharmacother 116: $109004,2019$.

40. Porta C, Paglino C and Mosca A: Targeting PI3K/Akt/mTOR signaling in cancer. Front Oncol 4: 64, 2014. 
41. Yang J, Ren X, Zhang L, Li Y, Cheng B and Xia J: Oridonin inhibits oral cancer growth and PI3K/Akt signaling pathway. Biomed Pharmacother 100: 226-232, 2018.

42. Zhu ML, Zhang PM, Jiang M, Yu SW and Wang L: Myricetin induces apoptosis and autophagy by inhibiting PI3K/Akt/mTOR signalling in human colon cancer cells. BMC Complement Med Ther 20: 209, 2020.

43. Zhou J, Xia L and Zhang Y: Naringin inhibits thyroid cancer cell proliferation and induces cell apoptosis through repressing PI3K/AKT pathway. Pathol Res Pract 215: 152707, 2019.

44. Yun CW and Lee SH: The roles of autophagy in cancer. Int J Mol Sci 19: 3466, 2018.

45. Towers CG, Wodetzki D and Thorburn A: Autophagy and cancer: Modulation of cell death pathways and cancer cell adaptations. J Cell Biol 219: e201909033, 2020.

46. Wei M, Wu Y, Liu H and Xie C: Genipin induces autophagy and suppresses cell growth of oral squamous cell carcinoma via PI3K/AKT/MTOR pathway. Drug Des Devel Ther 14: 395-405, 2020.

47. Zhou J, Jiang YY, Chen H, Wu YC and Zhang L: Tanshinone I attenuates the malignant biological properties of ovarian cancer by inducing apoptosis and autophagy via the inactivation of PI3K/AKT/mTOR pathway. Cell Prolif 53: e12739, 2020.
48. Raha S, Yumnam S, Hong GE, Lee HJ, Saralamma VV, Park HS, Heo JD, Lee SJ, Kim EH, Kim JA and Kim GS: Naringin induces autophagy-mediated growth inhibition by downregulating the PI3K/Akt/mTOR cascade via activation of MAPK pathways in AGS cancer cells. Int J Oncol 47: 1061-1069, 2015.

49. Liu WJ, Ye L, Huang WF, Guo LJ, Xu ZG, Wu HL, Yang C and Liu HF: p62 links the autophagy pathway and the ubiqutin-proteasome system upon ubiquitinated protein degradation. Cell Mol Biol Lett 21: 29, 2016.

50. Zhang YB, Gong JL, Xing TY, Zheng SP and Ding W: Autophagy protein p62/SQSTM1 is involved in HAMLET-induced cell death by modulating apotosis in U87MG cells. Cell Death Dis 4: e550, 2013.

This work is licensed under a Creative Commons Attribution-NonCommercial-NoDerivatives 4.0 International (CC BY-NC-ND 4.0) License. 